BRIEF REPORT

\title{
Severity of playground fractures: play equipment versus standing height falls
}

\author{
D Fiissel, G Pattison, A Howard
}

Injury Prevention 2005;11:337-339. doi: 10.1136/ip.2005.009167

Aim: To compare the severity of fractures from playground equipment falls to the severity of fractures from standing height falls occurring on the playground.

Methods: This case control study used data on all children presenting to the Hospital for Sick Children (Toronto) from 1995 to 2002 with a fracture due to a playground fall. Cases were children who fell from a height off playground equipment. Controls were children who fell from standing height on a playground. Fractures were major if they required reduction and minor if they did not.

Results: Fractures from equipment falls were $3.91195 \% \mathrm{Cl}$ 2.76 to 5.54 ) times more likely to require reduction than were fractures from standing height falls.

Conclusions: Major fractures were strongly associated with falls from playground equipment, whereas minor fractures came from both play equipment and standing height falls. Efforts to prevent major fractures should target playground equipment and the impact absorbing surface beneath it.

C hildhood play is essential for the development of cognitive, psychosocial, and physical skills and it is important that children be provided with safe play environments. Playgrounds are one area that provides opportunities for skill development, but severe playground injuries are common. Playground injuries are more severe than injuries from any other common childhood injury mechanism except traffic. ${ }^{1}$ In Ontario, the second leading cause of sports and recreational hospitalizations is falls from playground equipment. ${ }^{2} 28500$ children in Canada receive hospital treatment each year for playground related injuries. ${ }^{3}$ Fractures account for the majority (84\%) of hospitalizations. ${ }^{4}$ Although current playground safety standards (for equipment, height, and surfacing) address head injury well, ${ }^{5}$ recent attention has focused on improving testing and standards to address the large burden of upper extremity fractures. ${ }^{6-9}$

How safe can playground equipment be made? From a practical perspective, one could consider playground equipment safe if the injuries seen from equipment match the severity of those seen from standing height falls, as the latter would continue to occur in a playground free of equipment. Mayr et al reported that equipment falls were responsible for $57 \%$ of injuries seen, and standing height falls were responsible for $15 \% .^{10}$ They did not comment on whether the falls from equipment were of greater severity. A recent systematic review on playground safety stated "The available literature does not inform ... the interaction between height of fall, surface, and fracture type." ${ }^{\prime 5}$ The present study addresses the identified height to fracture severity knowledge gap by comparing the severity of fractures from playground equipment falls to the severity of fractures from standing height falls.

\section{METHODS}

The Canadian Hospital Injury Research and Prevention Program (CHIRPP) database was used to identify all fractures that resulted from a fall which occurred on a playground and presented to the emergency department at the Hospital for Sick Children between the years 1995 and 2002. CHIRPP data are collected via a questionnaire completed in the emergency department in which children and parents describe the nature of the injury (what went wrong, where, and how). Parent's free text written descriptions are coded into specific predefined categories of mechanism and protective factors (for example, for playgrounds, equipment categories of monkey bar/jungle gym, slides, swings, seesaws, and other structures). The examining physician records the type of injury and the type of treatment required (for example, treatment in the emergency department, admitted to hospital). Because of referral bias, CHIRPP data cannot be used to calculate rates, but can be used to characterize type and severity of injuries.

A case control study design was used; cases were children who sustained a fracture by falling from a height off playground equipment. Controls were children of the same age who sustained a fracture on a playground by falling from standing height. Playgrounds were limited to public playgrounds including those at schools, parks, and other institutions; falls occurring at home playgrounds were not included. The outcome was the severity of the fracture sustained and severity classification was based on the treatment received. Major fractures were defined as those fractures which required emergency room or operating room reduction whereas minor fractures were defined as those which did not. For example, a displaced supracondylar humerus fracture would be a major fracture whereas a distal radial buckle fracture would be a minor fracture. The odds (and 95\% confidence intervals) of having a major fracture were determined for falls from playground equipment compared with falls from standing height. Odds ratios were recalculated using age and sex adjustment (Mantel-Haenszel technique), using an alternative definition of major fracture ("requiring hospital admission"), and assuming all uncoded data maximally shifted the result towards the null, to test the robustness of the observation.

\section{RESULTS}

There were 3155 playground falls treated at the Hospital for Sick Children from 1995 to 2002. Of these, 1405 (44.5\%) were fractures. Of the 1405 fractures, 71 (48 minor and 23 major) were excluded because the fall, although from a height and on a playground, explicitly did not involve playground equipment (for example, trees, fences). Another 264 fractures related to falling from height were excluded because there was no information about where the fall occurred. The

Abbreviation: CHIRPP, Canadian Hospital Injury Research and Prevention Program. 
Table 1 Age and sex of the patients with fractures

\begin{tabular}{lll}
\hline Age group & Male & Female \\
\hline$\leqslant 4$ & 114 & 105 \\
$5-9$ & 352 & 302 \\
$10-14$ & 134 & 73 \\
$\geqslant 15$ & 12 & 3 \\
Total & $585(54.7 \%)$ & $484(45.3 \%)$ \\
\hline
\end{tabular}

Table 2 Anatomic location of fracture, by mechanism and severity

\begin{tabular}{lrrrrr}
\hline & \multicolumn{2}{l}{ Standing height } & & \multicolumn{2}{l}{ Equipment } \\
\cline { 2 - 3 } \cline { 5 - 6 } \cline { 5 - 6 } & Minor & Major & & Minor & Major \\
\hline Upper extremity & 238 & 42 & & 368 & 267 \\
Lower extremity & 56 & 6 & & 55 & 13 \\
Other & 7 & 2 & & 3 & 13 \\
\hline
\end{tabular}

remaining 1070 fractures from playground falls were all either standing height falls $(351,32.8 \%)$ or falls from playground equipment $(719,67.2 \%)$. Overall, $45.3 \%$ of the patients were girls, and $85.5 \%$ of the fractures were in the upper extremity. Further breakdown of patient characteristics and fracture locations is given in tables 1 and 2 .

Playground equipment falls represented the vast majority $(85 \%)$ of the major fractures (table 3 ). The odds of a major fracture were 3.91 times greater when the fall was from a piece of equipment compared with falls from standing height on the playground ( $\mathrm{OR}=3.91,95 \%$ CI 2.76 to 5.54). MantelHaenszel analysis stratified by age and sex yielded a similar odds ratio of 3.60 (95\% CI 2.48 to 5.20). Redefining major fracture as "requiring hospital admission" (instead of "requiring fracture reduction") and re-analyzing the data yielded a similar odds ratio of 3.21 (95\% CI 2.19 to 4.71 ) (table 4). A sensitivity analysis assuming all 264 unspecified falls from height were minor fractures from play equipment (that is, maximally biased toward the null hypothesis) still yielded a statistically significant increase in the odds of a severe fracture for falls from playground equipment.

Table 3 Number of minor and major fractures by type of fall. Major fracture is defined as "requiring reduction"

\begin{tabular}{lrll}
\hline \multicolumn{2}{l}{ Fracture severity Standing height } & Play equipment & Odds ratio \\
\hline Minor fracture & 301 & 436 & \\
Major fracture & 50 & 283 & 3.91 (2.76-5.54) \\
Total & 351 & 719 & \\
\hline
\end{tabular}

Table 4 Alternative definition of major fracture as "requiring hospital admission" with re-analysis of relation between fall type and fracture severity

\begin{tabular}{lrll}
\hline \multicolumn{2}{l}{ Fracture severity Standing height } & Play equipment & Odds ratio \\
\hline Minor fracture & 311 & 509 & \\
Major fracture & 40 & 210 & 3.21 (2.19-4.71) \\
Total & 351 & 719 & \\
\hline
\end{tabular}

Table 5 lists the specific type of equipment that the fractures occurred on. Each equipment subtype had a significantly higher odds of major fracture compared with standing height falls. Monkey bars/jungle gyms were responsible for the largest numbers of fractures, accounting for $60.8 \%$ of the major fractures and $56.7 \%$ of the minor fractures sustained.

\section{DISCUSSION}

Playground equipment falls produced a substantially greater number of more serious fractures compared with falls from standing height on the playground. Children who fell from equipment were four times more likely to sustain a severe fracture than were children who fell from standing height.

Previous research that has shown that falls from playground equipment most often account for the greatest number and the most severe injuries in playgrounds, with many injuries resulting from falls off monkey bars. ${ }^{41-14}$ For example, Macarthur et al ${ }^{15}$ examined the severity of injuries associated with falls from playground equipment and found that the more severe injuries resulted from falls from hanging equipment, such as monkey bars. Similarly, Laforest et al ${ }^{16}$ examined injury severity from playground falls and found that both the height of the equipment and the surface under the equipment were related to severity of injury. However, in both of these studies, the "severe" injury category was heterogeneous and included all fractures, not just fractures requiring emergency room or operating room reduction.

Fractures, particularly in childhood, are a fairly common occurrence. Estimates of the annual incidence rates for a fracture in childhood range from 12 to 42 per thousand children per year. ${ }^{17-19}$ Among girls, 37-39\% will sustain a fracture during childhood; among boys $43-64 \%$ will. ${ }^{18}{ }^{19}$ Few children have any permanent sequelae, and most of these fractures are minor

Our study extends the playground injury literature by demonstrating a strong association between playground equipment falls and major fractures. Although minor fractures were seen from both equipment and standing height falls, the vast majority $(85 \%)$ of major fractures came from play equipment falls. These major fractures involve more pain, more surgical care, and a higher risk of nerve and vessel injury, infection, and impaired function.

To our knowledge, no research has examined the parental perspective concerning the types of fractures considered "normative" or "acceptable" for children and those considered "unacceptable" and in need of prevention programming. Evidence does exist that suggests parents are influential in injury prevention activities and do not consider all injuries preventable. ${ }^{20-23}$ Since 40 to $60 \%$ of children will have a fracture it is possible parents consider some fractures normative, but we assume that parents would deem the major fractures from playground equipment falls worthy of prevention efforts.

There are limitations to this study. Our sample consisted of children who visited the Hospital for Sick Children, a pediatric tertiary care centre. We may see a higher proportion of severe injuries because of referral bias. Referral bias, however, should not differ according to injury mechanism (equipment $v$ standing height) so should not produce a false positive result. Another limitation of the study is that data regarding how the child was injured are based on parental reports. There is no external validation of the accuracy of this data. Finally, there is no information in this type of surveillance data regarding exposure. It is impossible to know how many children play on playground equipment and which types of equipment are most frequently used. Nixon et $a^{24}$ reported that monkey bars resulted in the greatest number of injuries $(52.1 \%)$ presenting to the emergency 
Table 5 Number of minor and major fractures by type of play equipment

\begin{tabular}{lccc}
\hline Mechanism of fall & Minor fracture (\%) & Major fracture (\%) & Odds ratio (CI) \\
\hline Monkey bars, jungle gyms, etc & $247(58.9)$ & $172(41.1)$ & $4.19(2.89-6.09)$ \\
Other structure & $68(68.7)$ & $31(31.3)$ & $2.74(1.58-4.76)$ \\
Slides & $72(58.5)$ & $51(41.5)$ & $4.26(2.60-6.99)$ \\
Swings/swing sets & $42(66.7)$ & $21(33.3)$ & $3.01(1.58-5.73)$ \\
Seesaws & $7(46.7)$ & $8(53.3)$ & $6.88(2.15-22.25)$ \\
Standing height & $301(85.8)$ & $50(14.2)$ & \\
\hline
\end{tabular}

department, yet only accounted for $15.9 \%$ of the equipment. However, it should be noted that Nixon et al found monkey bars to be the most heavily used equipment, being used approximately 150 times a day. Thus, the level of exposure to different types of equipment may be an important factor to consider when designing interventions to prevent playground related injuries.

We used a different cut off for injury severity than have other authors. Other authors have defined AIS 2 and above injuries as severe. ${ }^{15} 16$ Our cut point ("requiring reduction") classifies many AIS 2 injuries (undisplaced fractures) as minor injuries, and AIS 3 injuries (displaced fractures, open fractures, nerve or vessel injury) as major injuries. Our alternative cut point ("requiring hospital admission") showed that the main effect we observed was robust. Although some have argued that any playground fracture is severe, we feel that the high incidence of childhood fractures, and the high number of fractures from standing height, merits our closer look at the severity of playground equipment fractures.

In conclusion, children are at risk for fractures of greater severity when using playground equipment, as opposed to engaging in other activities on the playground that are done at a standing height. Given that fractures are a common occurrence of childhood, the question becomes how to prioritize prevention. Major fractures were strongly associated with falls from playground equipment, whereas minor fractures came from both play equipment and standing height falls. Efforts to prevent major fractures should target playground equipment and the impact absorbing surface beneath it.

\section{Key points}

- Playground falls are a common cause of upper extremity fractures.

- It is not known whether play equipment falls produce a preponderance of severe fractures compared with standing height falls on the playground.

- Falls from playground equipment are four times more likely to result in severe fractures than falls from a standing height on the playground.

- Efforts to prevent major fractures should target playground equipment and the impact absorbing surface beneath it.

\section{Authors' affiliations}

D Fiissel, A Howard, The Hospital for Sick Children, Toronto, Canada G Pattison, University of Warwick Medical School, Coventry, UK
Correspondence to: Dr A Howard, The Hospital for Sick Children, 555 University Avenue, Room S-107, Toronto, ON, M5G 1X8, Canada; andrew.howard@sickkids.ca

Accepted 10 August 2005

\section{REFERENCES}

1 Yamamoto LG, Wiebe RA, Matthews WJ Jr. A one-year prospective ED cohort of pediatric trauma. Pediatr Emerg Care 1991;7:267-74.

2 Canadian Institute for Health Information (CIHI). Ontario trauma registry analytic bulletin: Sports and recreational injury hospitalizations in Ontario, 2002-2003 2004

3 Safe Kids Canada. Playground safety fact sheet, 2004. Available at www.safekidscanada.ca (accessed October 2005)

4 CHIRPP Injury Reports. Injuries associated with playground equipment 1998

5 Norton C, Nixon J, Sibert JR. Playground injuries to children. Arch Dis Child 2004;89:103-8.

6 Sherker S, Ozanne-Smith J. Are current playground safety standards adequate for preventing arm fractures? Med J Aust 2004; 180:562-5.

7 Sherker S, Ozanne-Smith J, Rechnitzer G, et al. Development of a multidisciplinary method to determine risk factors for arm fracture in falls from playground equipment. Inj Prev 2003;9:279-83.

8 Gunatilaka AH, Sherker S, Ozanne-Smith J. Comparative performance of playground surfacingmaterials including conditions of extreme noncompliance. Inj Prev 2004:10:174-9.

9 Sherker S, Ozanne-Smith J, Rechnitzer G, et al. Out on a limb: risk factors for arm fracture in playground equipment falls. Inj Prev 2005;11:120-4.

10 Mayr J, Russe O, Spitzer P, et al. Playground accidents. Acta Paediatr 1995:84:573-6.

11 Mott A, Evans R, Rolfe K, et al. Patterns of injuries to children on public playgrounds. Arch Dis Child 1994;71:328-30

12 Mott A, Rolfe K, James R, et al. Safety of surfaces and equipment for children in playgrounds. Lancet 1997;349:1874-6.

13 Junkins EP Jr, Knight S, Lightfoot AC, et al. Epidemiology of school injuries in Utah: A population-based study. J Sch Health 1999;69:409.

14 Mack MG, Thompson D, Hudson S. An analysis of playground surface injuries. Res Q Exerc Sport 1997;68:368-72.

15 Macarthur C, Hu X, Wesson DE, et al. Risk factors for severe injuries associated with falls from playground equipment. Accid Anal Prev 2000;32:377-82.

16 Laforest $S$, Robitaille $Y$, Lesage $D$, et al. Surface characteristics, equipment height, and the occurrence and severity of playground injuries. Inj Prev 2001;7:35-40.

17 Moustaki M, Lariou M, Petridou E. Cross country variation of fractures in the childhood population. Is the origin biological or "accidental"? Inj Prev $2001 ; 7: 77$

18 Lyons RA, Delahunty AM, Kraus D, et al. Children's fractures: A population based study. Inj Prev 1999;5:129-32.

19 Jones IE, Williams SM, Dow N, et al. How many children remain fracture-free during growth? A longitudinal study of children and adolescents participating in the Dunedin Multidisciplinary health and development study. Osteoporos Int 2002;13:990-5.

20 Morrongiello BA, Dayler LA. A community-based study of parents' knowledge, attitudes and beliefs related to childhood injuries. Can J Public Health 1996:87:383-8.

21 Morrongiello BA, Hogg K. Mothers' reactions to children misbehaving in ways that can lead to injury: implications for gender differences in children's risk taking and injuries. Sex Roles 2004;50:103-18.

22 Morrongiello BA, Ondejko L, Littlejohn A. Understanding toddlers' in-home injuries: I. Context, correlates, and determinants. J Pediatr Psychol 2004;29:415-31

23 Morrongiello BA, Ondejko L, Littlejohn A. Understanding toddlers' in-home injuries: II. Examining parental strategies, and their efficacy, for managing child injury risk. J Pediatr Psychol 2004;29:433-46.

24 Nixon JW, Acton CHC, Wallis B, et al. Injury and frequency of use of playground equipment in public schools and parks in Brisbane, Australia. Inj Prev 2003;9:210-13. 